\title{
The "new" experimentalism? Women in/and/on film
}

Book or Report Section

Published Version

Chamarette, J. ORCID: https://orcid.org/0000-0003-0701-1514 (2015) The "new" experimentalism? Women in/and/on film. In: Feminisms. Amsterdam University Press, Amsterdam, pp. 125-140. ISBN 9789048523634 doi: https://doi.org/10.1515/9789048523634-013 Available at http://centaur.reading.ac.uk/92944/

It is advisable to refer to the publisher's version if you intend to cite from the work. See Guidance on citing.

To link to this article DOI: http://dx.doi.org/10.1515/9789048523634-013 Publisher: Amsterdam University Press

All outputs in CentAUR are protected by Intellectual Property Rights law, including copyright law. Copyright and IPR is retained by the creators or other copyright holders. Terms and conditions for use of this material are defined in the End User Agreement. 


\section{www.reading.ac.uk/centaur}

\section{CentAUR}

Central Archive at the University of Reading

Reading's research outputs online 


\section{Chapter Title: The "New" Experimentalism? Women In/And/On Film \\ Chapter Author(s): Jenny Chamarette}

Book Title: Feminisms

Book Subtitle: Diversity, Difference and Multiplicity in Contemporary Film Cultures

Book Editor(s): Laura Mulvey and Anna Backman Rogers

Published by: Amsterdam University Press

Stable URL: https://www.jstor.org/stable/j.ctt16d6996.15

JSTOR is a not-for-profit service that helps scholars, researchers, and students discover, use, and build upon a wide range of content in a trusted digital archive. We use information technology and tools to increase productivity and facilitate new forms of scholarship. For more information about JSTOR, please contact support@jstor.org.

Your use of the JSTOR archive indicates your acceptance of the Terms \& Conditions of Use, available at https://about.jstor.org/terms

CC This content is licensed under a Creative Commons Attribution-NonCommercial-NoDerivatives

(C) $\$ \Theta 9$ 4.0 International License (CC BY-NC-ND 4.0). To view a copy of this license, visit

BY NC ND https://creativecommons.org/licenses/by-nc-nd/4.0/. 


\section{PART III}

\section{History and Practice}


This content downloaded from

86.25.46.200 on Thu, 08 Oct 2020 18:49:44 UTC

All use subject to https://about.jstor.org/terms 


\title{
The "New" Experimentalism? Women In/And/On Film
}

\author{
Jenny Chamarette
}

\section{A Note on Positioning}

As a scholar whose work often turns toward feminist, phenomenological, and situated approaches to the moving image, I have in the past been accused of "cherry-picking" the artists and works with which I think and write. In a sense, this is absolutely correct. My studies tend to rely on serendipity and an openness to new encounters with creative expression, in examples that are rarely constricted by singularities of form and categories of scholarly discipline. Consequently I have found myself described both as a dabbler and a dilettante. But I prefer to be described as restless: this latter term acknowledges my reluctance to situate myself comfortably within the well-worn pathways of disciplinary structures in the humanities. My writing here, in a volume about women, Woman, and the multiple crossroads of feminisms in 2Ist-century Film Studies, continues these peregrinations.

I cannot claim that the recent moving image works of Shirin Neshat and Gillian Wearing bear close resemblances in their formal structures or theoretical concerns. While they are both living contemporary artists working with the moving image, there is relatively little that connects them structurally or thematically. I do not consider gender alone to be a uniting force for their thinking and creativity, and I certainly do not wish to relegate their endeavors to some sort of biological essentialism. However, I want to draw attention to their work for emotional and intellectual reasons. First, I have been moved by and drawn to works by both artists over the past few years of research in contemporary film and art. Second, the serendipitous collision of creative concepts is one of the most fruitful ways in which feminism has made interventions in studies of film, and art. Some of the finest examples of this can be seen in the writing of Sara Ahmed, Mieke Bal, Laura U. Marks, Laura Mulvey, Griselda Pollock, and Emma Wilson. ${ }^{\mathrm{I}}$ A close examination of two female artists working with the moving image requires an understanding of their respective ethical, political, and aesthetic concerns, but also a closer engagement with feminist philosophy and feminist critical studies in the light of experimental filmmaking by and about women. 
This opening note is therefore a caveat emptor on my own positioning as a feminist phenomenological critic, on the ways in which I arrange sets of feminist and gendered critical discourses around Neshat, Wearing, and others, and on the orientations of self-positioning and ways of looking at the world that emerge in these works as I explore them. Unfortunately, the scope of this chapter cannot permit a comprehensive exploration of female experimental filmmakers. Perhaps to do so would also risk essentializing to designations of gender the achievements of artists as varied as Peggy Ahwesh, Sadie Benning, Abigail Child, Julie Dash, Maya Deren, Germaine Dulac, Su Friedrich, Barbara Hammer, Jennifer Montgomery, Alexandra Navratil, Jennifer Reeves, Lis Rhodes, Aura Satz, Joyce Wieland, and so on. I admire the work, inter alia, of scholars such as Catherine Elwes, Lucy Reynolds, and Robin Blaetz, ${ }^{2}$ journals such as Millenium Film Journal and Moving Image Review and Art Journal, and film organizations such as Cinenova and Electra in the UK, and the Centre Audiovisuel Simone de Beauvoir in France ${ }^{3}$ who have brought to the attention of the scholarly and artistic community the importance of women's often underappreciated contributions to experimental forms of cinema. Nonetheless, here I hope that, by bringing together feminist philosophies of the image, and the experimental film work of two contemporary female artists, open encounters between these works will help to explore new territories of feminism and experimental film.

\section{In/And/On}

I want to draw attention to the conjunctions of this essay's title: women in experimental film, women and experimental film, women on experimental film. The prepositions and conjunctions of relation - that is, women's relation to their social, political, and embodied situations - have constituted both a historical interest and an ongoing issue of debate in feminist scholarship. ${ }^{4}$ The conjunction "women and experimental film" cannot be reduced to the descriptor of "women's film." Consequently, just as I have made clear my own positioning with regard to the works I explore in this essay, I also want to make clear the purpose of the relations I am setting up in each case.

Women in experimental cinema become the dominant orientations of my thoughts in the case of Shirin Neshat's oeuvre. Her work itself emphasizes both female representation - in a manner drawing comparison with other contemporary Iranian cinema, as some have argued ${ }^{6}$ - and Neshat's own identity as a female Iranian artist working in experimental film and artists' moving image. By exploring Neshat's position as a woman in experimental filmmaking, I also acknowledge the ways that tensions arise between these two poles of identity: "Iranian cinema" on the one hand and "feminist experimental filmmaker" on the other. For instance, in relation to Neshat's work, we might contest the position of "Iranian cinema" as a diasporic concept, or indeed at best an example of 
"good Orientalism," introducing Anglo-European audiences to an unfamiliar cultural imaginary rather than containing at heart an "authentic voice" of Iran. ${ }^{7}$

I turn to the conjunction of women and experimental cinema in Gillian Wearing's recent feature film SELF MADE (2010), not least because polarizations of gender are less prevalent in her work than in Neshat's. Instead, relations and conjunctions of gender, race, and socio-economic status are emphasized through constructions of onscreen performance. In using the term "and," I also recognize Wearing's different trajectory to that of Neshat: while the stylized aesthetic of WOMEN WiTHOUT MEN (2009) brings Neshat's presence as artist to the fore, Wearing's performative documentary renders her directorial presence almost invisible, and instead encourages more detailed attention to the trajectories of performance in the film. As a result, the collaborative performances of individuals within Wearing's film, SELF MADE, bring about distinctions of class, race, and gender. Consequently, they raise questions of intersection and conjunction, which inevitably give rise to an understanding of difference as a crucial element both of contemporary intersectional feminist discourses and contemporary experimental film practice.

Lastly, it is important to address the notion of what is, if anything, "experimental" about the kinds of cinema produced by Wearing and Neshat. In each case, I discuss a recent feature-length film whose conditions of distribution and exhibition resemble almost seamlessly the "art cinema" of well-established female directors such as Chantal Akerman, Jane Campion, Samira Makhmalbaf, Haifaa al-Mansour, Sally Potter, Lynne Ramsay, Kelly Reichardt, Monika Treut, and Agnès Varda, among others. However, one potential indicator for experimentation, or indeed, experimentalism, in Neshat and Wearing's work, is the transition that both artists have recently made from photography, video art, and moving image installation to feature-length, internationally distributed film, exhibited in cinemas. I would like to suggest that my encounters with the work of these two artist-filmmakers have resonances with a broader move in experimental filmmaking, away from the gallery and back into the bright-lit festivals and darkened auditoria of cinema. If this is a "new experimentalism" for the cinematic arts, then it also allows the recent work of other artists (Miranda July, Tejal Shah, Sam Taylor-Wood) to be considered along these lines.

\section{Women In Film: On Not Looking the Same Way with Shirin Neshat}

A young woman dressed in a pale summer dress, a black chador flowing down from her head, crouches close to the ground, her hands cupped around a charmed object. Shaded greenery frames this lone woman: we are in a courtyard garden to a large home, rhythmic music emanating from an entrance strung with colored lights in preparation for wedding festivities. Hidden by her black cloak and invisible to those preparing the wedding feast behind her, the young wo- 
man's gestures are concentrated, enclosed, as she murmurs an incantation under her breath, filmed in close-up and filling the right-hand side of the frame. As a viewer of Shirin Neshat's feature-length film, WoMEN Without MEN, I am invited to sit in front of this woman as she crouches low and motionless, through the camera's lens. A voice whispers a name: Faezeh. The muted drumming halts abruptly: without moving, we have shifted into a different space, a half-world. She recognizes her name, turns, snatching up the object she had laid on the ground, fearing that she has been discovered. There is no one. Only the birdsong and the close-miked sound of the woman's breathing and digging remain. The voice calls her name again, and a third time.

A swift edit to another close-up of Faezeh's face then cuts away once more to a low level, medium shot - a full composition reminiscent of the perspectival tableaux of Persian miniatures (the medium in which Neshat first developed her artistic practice, in fact), but perhaps also a somber version of the tableaux of the late Igth-century French painter, Henri Rousseau. Within this tableau, Faezeh scrambles forward, confronting the screen and the ground, falling to her hands and knees. Feeling along the soil with her hands, she seeks out the source of that familiar voice, from underneath the soil that she had, moments before, been carefully scraping away in order to bury her enchanted object. She begins to dig - to the right, the middle, and the left of the frame - directed by that ghostly, interred voice. Rapid cuts between her distressed face, her ragged breathing, her scrabbling hands, amplify the emotional intensity of the scene: there is someone, buried alive, or resurrected, below the surface of the earth. My spectatorial positioning situates me with her, alongside her - not through her eyes, but intimately close to the earth and to her hands. With swift movements, she unfolds layers of black cloth, revealing a woman's face: eyes closed, mouth open, dust streaked across her chin, cheek, and nose. A death mask.

Faezeh's rapidly tunneling hands reveal more cloth - a body, a glimpse of skin and flesh that becomes a hand - open palm upturned in grace or forgiveness. Her hand brushes across that of the buried woman, and as extradiegetic ascending piano and strings play out a very different, mournful rhythm to the upbeat drumming at the beginning of the scene, another cut reveals the initially lifeless woman to be breathing, as if breathing again for the first time. Holding both of her hands, Faezeh lifts her up, out of the earth, and the woman, her friend Munis, opens her eyes and gazes toward her. Now at a distance and hidden behind green foliage, we see the buried woman stand, her chador falling to her feet. In a I8o-degree cut, she strides determinedly, her back to us, towards a pool of water. The lapping waters, crisply invoked through the film's soundtrack, consume her as she enters the pool, and a final, symmetrical, beautifully choreographed image from directly above closes the sequence, revealing a still frame within which $\mathrm{Mu}$ nis's body is submerged underwater, the skirts of her dress enveloping her, transforming her into a rose-like abstract image. 
What is the purpose of this eager account of a segment of Neshat's film? Perhaps to illustrate a point. The description above accommodates, albeit idiosyncratically, the expectations of film analysis, drawing attention to detail, narrative, and spectatorial responses to the formally complex aesthetics of WOMEN WITHOUT MEN. By its nature, it attempts to describe the sequence from a semi-omniscient perspective, assuming that my own analytic description of the sequence would resemble those of others who have viewed the film. It is clear that affect is at work in this sequence. Cuts force the spectator to alternate between close proximity to the bodies of the protagonists, and a distanced, tableau-like composition, confusing and constricting the flows of identification or empathy that might be invoked if we were to stick closely, through our vision, to these women's bodies. But can it really be true to say that this sequence is universally affecting? Particularly in a film that sits at the interstices of Iranian and AngloAmerican cultures - presenting Iran, but funded and distributed within a firmly Euro-American context - can it be assumed that the affect I experience necessarily constitutes collective affective responses beyond me? Can there be a collective "we" in the context of engaging with this film? These become feminist questions both of authorship and of spectatorship by virtue of Neshat's own concerns with the visibility of women in Iranian culture. Moreover, it becomes feminist, because feminism shares with postcolonial discourses of race, ethnicity, and hybridity an ethical attentiveness to issues of collectivity and issues of difference.

Neshat, an exiled Iranian visual artist based in New York, carries a distinctive voice, and significant commercial success, within international contemporary art. As an artist who extensively appropriates and critiques both the symbolisms of Persian culture, Islamic monotheism, and Christian rhetorics of flesh, mourning, and incarnation, Neshat was banned from returning to Iran following the exhibition of her first major work, Women of Allah (I993-I997). This controversial series of photographic portraits depicted high-contrast, black-and-white images of veiled women holding firearms or otherwise demonstrating their political resistance and, according to Neshat, female Shi'a martyrdom. ${ }^{8}$ Handwritten poetic and political verses in Farsi by contemporary Iranian women poets were superimposed over partially revealed faces, palms, and feet. The works themselves were considered incendiary in Iran and consequently resulted in both Neshat and her work being banned in Iran in $1996 .^{9}$

Despite the international critical acclaim of her photography, video installations, and films, Neshat's work is still not shown in Iran. Neshat clearly identifies with her position in the Iranian diaspora, and her status as exile is frequently discussed in interviews and scholarship on Neshat. Much of Neshat's work is concerned with the conjoining of structural opposites: male and female, the real and the magical, formal stillness and choreography, political concreteness and poetic abstraction. Ranjana Khanna describes the image of woman in Neshat's work as invoking mutually contradictory and mutually conjoined conditions: 
A face partially covered with a burqa, and inscribed with a poem you may or may not understand, nonetheless produces both a target and a threat, someone dead and alive, devout and defiant, propagandist and revolutionary, pure and complicitous, the martyr and the target, still and without space to move from the frame. All the images, with eyes inscribed or without eyes at all, seeing or blind, appear as a death mask. Never an identity, she is always an image, a singular-plural transcribed, transcribable, both located and definitely not. $^{\text {IO }}$

Although Khanna here discusses Neshat's first series of photographs, Women of Allah, the resonances with WOMEN WiTHOUT MEN are apparent. The young women on screen in the sequence I described earlier are two of four female protagonists, each trapped or constrained in some way by the film's stylized vision of Tehran just prior to the British and American engineered military coup in I953. Tracing the respective journeys of Faezeh, the devout young woman; Munis, an activist and Faezeh's close friend; Zarrin, a young prostitute; and Fakhri, a wealthy wife of an eminent military leader, the film alternates between Tehran and a semi-magical orchard garden beyond the city's borders. The garden becomes a retreat of safety for all four women, only for that peace and communal cohabitation to be destroyed by an influx of Fakhri's moneyed friends, and the eventual arrival of the military, followed by the police. The location of the two women in the sequence I have described is therefore both specific and symbolic, situated both within the world of a modernized, secular Tehran just prior to the coup, and beyond it, since the mythical garden of the sequence is saturated with iconic references to both European and Persian art, and is replete with both Christological and Islamic symbolism of resurrection and rebirth.

As Laura U. Marks has pointed out, exiled artists working between the contexts of the Middle East and America/Europe are frequently caught up in a "thick intercultural fabric spanning home and diaspora." stances, the kinds of feminist practices most likely to be visible in such works are predominantly Anglo-European in orientation, constituting a kind of "good Orientalism" that "does not pretend to be objective [and is] intended for Western audiences, to educate them about matters that are self-evident to Arab audiences or simply that concern Westerners more than Arabs." ${ }^{12}$ While Marks specifically refers to Arab women filmmaking in the article cited above, her concern with "good Orientalism" crosses over into other Middle Eastern cultures, including Iranian and/or Persian ones. Consequently, the notion of Neshat's intercultural work educating Western audiences, through a reappraisal of traditional Iranian visual tropes, becomes an important means of negotiating but not ignoring the apparent divides between spectatorial attitudes, moral judgments, and female representation in her work. 
Neshat completed Women Without MEN, her first feature length film, in 2009, with funding from a range of European film funding initiatives. Shifting against a contemporary tide of filmmakers moving from cinema to gallery and artist's moving image, Neshat instead moves from the gallery to cinema - and more particularly still, to cinemas caught up within the complex industrial matrix of the film festival. WOMEN Without MEN was well received, picking up the Silver Lion for Best Director at the 2009 Venice Film Festival. Delivered in Farsi, the film is a loose adaptation of a contemporary novel by Iranian writer Shahrnush Parsipur. Parsipur, who had been imprisoned by the Iranian authorities a number of times during her life, was imprisoned once again after the publication of her book, because of its discussions of female sexuality and virginity. Neshat's film, banned from exhibition in Iran, like all of her work, similarly deplores the impossibly restrictive positions of women both prior to and immediately after the military coup that forced out the democratically elected Prime Minister, Mohammad Mosaddegh in I953, and transferred power overwhelmingly to the Shah, who remained absolute monarch for the next 26 years. The protagonist rising from the dead in the sequence I introduced initially is a young woman who kills herself in order to be free of the constraints of her life, fulfilling her wish to become a political activist in her immortal body. In as much as WOMEN WITHOUT MEN negotiates mutually contradictory positions, such as the (un)dead female activist, it also refuses conventions of narrative time and place. Historical Tehran blends seamlessly with a fantastical garden orchard. The garden is large enough to serve as a sanctuary for the women, and yet the passage between Tehran and the garden is timeless and unhindered by the physical demands of walking long distances in the desert. The crepuscular, blue-ish hues of the film barely reach into the realm of color at times: flesh-tones are as pale as sand; forests are like shadows.

The aesthetic poles in Neshat's work also play out in binary oppositions, particularly in the manner in which she examines the cross-cultural and countercultural particularities of Iranian and Western Anglophone culture. In an interview in 1999 , Neshat states that:

I function as a translator, conveying the meaning of one culture to the other as I find a visual language to communicate to both sensibilities. The two cultures aren't merely different; they are completely contradictory. [...] The work has helped me zero in on the cultural differences, such as in matters of religion and equal rights, but also to address the universality of basic human events that take place in the world simultaneously, like the revulsion that comes from being controlled by governments - social, political or religious codes and to address the bottom line that we all have emotions which are less cultural than natural. ${ }^{13}$ 
It is precisely the bi-cultural enframing of Neshat's work that has attracted significant critical attention. ${ }^{\mathrm{I}}$ In her statement above, Neshat opposes affect to culture, superposing them in a hierarchical relationship to one another. She suggests that emotions are a "natural" state, which she sets up as an ethical and shared alternative to polarized Iranian and Anglo-European cultural frames. And yet, it seems that the placement of the emotions within the realm of the "natural" allows a notion of "nature" to become interchangeable with a notion of the universal; "culture" remains the preserve of the particular. Furthermore, by describing emotion as natural, she also suggests that affect does not dwell within the house of culture, but rather that it sits beyond it, as a transcendent quality. Nonetheless, in the context of a film that is both symbolically and iconically rich, but which pertains to a hybrid cultural context of what Hamid Naficy would describe as accented cinema, ${ }^{15}$ the prescient issues of attempting to recuperate an Iranian identity, while acknowledging an incommensurable distance from contemporary Iranian culture do not seem to be easily rectified through claims of universal or transcendental affect.

I take as a launch point for this question of "universal affect" an engagement with the recent work of the French philosopher of the image, Marie-José Mondzain. Mondzain is a prominent figure in France in aesthetics and the history and philosophy of cinema and the image, alongside eminent peers such as Jean-Luc Nancy, Jacques Rancière and Georges Didi-Hubermann. ${ }^{\text {I6 }}$ However, compared to these other writers, her work has limited availability in English translation. Perhaps most well known for her essay, "Can Images Kill?" ${ }^{17}$ Mondzain's domains of inquiry reach across histories and iconographies of the image, from the gestures and behaviors of prehistoric humans in Homo Spectator ${ }^{18}$ to religious icons and the crisis of iconoclasm in the Byzantine Empire in Image, Icon, Economy: The Byzantine Origins of the Contemporary Imaginary ${ }^{\mathrm{Ig}}$ to contemporary cinematic ethics in Images (à suivre). ${ }^{20}$ Neshat's comments about the "natural" affective power of her images bear close resemblance to Mondzain's claims about visibility and the ability of the visible world, image or realm to connect to our affective lives. In "Can Images Kill?" Mondzain writes:

The visible touches us insofar as it deals with the power of desire and obliges us to find the means to love or to hate collectively. Visibility encourages minds and bodies to have a constructive or destructive dialogue with such violence [...]. It is incumbent upon us to know where and how the violence of our images generates the force that is needed to live together. ${ }^{2 r}$

For Mondzain, then, affective collectivity demands ethical responsibility. The ethical possibility of living together is subtended by the implicit possibility of violence, and affect is a means of provoking and creating dialogue with this violence. Visibility - the possibility of looking - is in fact always subtended by the 
affective awareness of violence: that awareness creates the possibility for collective experience. In 2007, Mondzain published a short article in the Cahiers $d u$ cinema on the Iranian filmmaker-artist Abbas Kiarostami's installation, LooKING AT TAZIEH, which reconfigured a recorded performance of the Iranian Shi'a passion play known as the Ta'zieh. Mondzain describes the installation as a way of seeing differently. She writes: "Culture appears here as that which, in its respect for difference, produces a relationship of universal recognition between subjects." ${ }^{22}$ I want to suggest that Mondzain argues the following: affective responses to cultural constructs create a recognition of cultural difference. It is this recognition of difference, rather than affect, or indeed culture, which in turn produces a universal commerce of intersubjective encounters. As such, it is the recognition of difference, rather than the sharing of cultural perspectives or affective experiences which creates the possibility of any kind of relationship between spectators and performers. Thus their positioning in Western or Eastern viewing traditions is not irrelevant, but rather deeply implicated in the possibility of mutual recognition as subjects, through cultural difference.

According to Mondzain, affect is a ground from which cultural difference emerges, and by consequence it is not a product of culture. Somewhat counterintuitively, in both Neshat's discussions and Mondzain's, the positioning of difference seems to bring to bear something very important about affect: affect invites, evokes, and produces difference, not similarity. There is nothing, then, that I can claim about what I feel (even about a sequence as emotionally evocative and powerful as the sequence I described at the beginning of this section) that can assume as a basis for my argument, that an other - you, the reader, for example can feel it too. In fact, whatever I feel will only bring about an acute awareness of the cultural differences, large or small, oppositional or contradictory, between the ways in which you and I experience affect in the world. There is no "we" that defines, constructs or invokes affective encounters universally. Neshat's film, WOMEN Without MEN, reveals affective non-commensurability by expanding its frames of reference, and particularly by negotiating the image regimes and monotheistic symbolisms of both Western Anglophone secular culture and Shi'a Islam. Effectively, the film produces an affective distance between the "we" and the "I" through its intertwining of cultural difference.

Neshat's positioning as a diasporic Iranian artist gives a particularly acute insight into the bicultural relationalities and contradictions that WOMEN WITHOUT MEN provokes. If affect is something that subtends cultural difference, and if an understanding of cultural difference is predicated upon affect, then affect is not necessarily a natural and thus universal quality. Instead, it is a condition of possibility for cultural difference to be acknowledged at all. In this case, affect invoked through the filmic image might be more appropriately described as an unachievable striving for shared emotional experience that in its failure establishes an ethics of living within a world of cultural contradiction. My extension 
of Neshat's work and Mondzain's writing suggests that we can neither look the same way, from the position of our enculturated bodies, nor can we feel the same way, even through affectively powerful moments in film and art. Nonetheless, by not looking or feeling the same way, and perhaps by never doing so, the incommensurabilities of our affective conditions help us to understand better the ethics of our looking, which is ultimately an ethics of living together.

Gender has been a primary concern for Neshat's moving image works, not least in her video installations Turbulent, (I998), RAPTURE (I999) and FERVOR (2000), and this becomes particularly prominent in WOMEN WITHOUT MEN's tentative representation of a utopian matriarchy. ${ }^{23}$ However, to think exclusively about the representation of women in the film would risk obscuring the positioning of Neshat as a woman working in the medium of film, through video art, high definition installation, and feature length fiction. This concern with regard to WOMEN Without MEN, as I have outlined through a reading of Mondzain, is more powerfully connected to the ways in which Euro-American feminisms interact with iconographies of Persian cultures; in other words, what is made visible in the culture clash that emerges in Women Without MEN. These interactions between Western feminism and Persian politics might make claims for the semblances of shared affect - and particularly so in the beautiful, muted, often minimalist images of Neshat's film. But those conditions for collectivity are also underpinned by violence, and the rapid undoing of any claims for universal or shared feeling. When Faezeh uncovers Munis's undead body in the sequence I initially described, there is a complex metaphorical link between the living and undead female body, the potential for shared space, time, and emotion for Iranian and European femininity, and the always-failing potential of "good Orientalism" to produce a shared emotional space - in effect, empathy. If, then, we can think of affect, not as universal or shared, but as a disconnective interface - or a chiasmic encounter, in phenomenological terms - then the problem of "we" is only a problem when we imagine that we all look and feel the same.

\section{Women And Film: Difference, Performance, and Gillian Wearing}

These problems of sameness, and of the limits of empathy, are issues I would like to take further through engagement with a recent feature film by Gillian Wearing. In my discussions so far, I have turned first towards affect as a way of accounting for cultural and gender difference in Shirin Neshat's work. Implicitly, my account critiques the possibility of a "collective feminism" that elides the violent collisions of culture and politics, particularly within regimes of the image. As I mentioned at the outset, I cannot claim that Neshat and Wearing share connected values or discourses simply by virtue of their position as women making experimental and art film. However, the manner in which I discuss the work 
of both filmmakers in relation to feminist and cultural discourses around difference does contribute to important ongoing debates in feminist film studies, particularly with relation to the intersections of gender, culture, and ethnicity.

SELF MADE came out in 20I0, one of the last funded projects from the UK Film Council as was, together with Arts Council England and the Channel 4 Britdoc Foundation. A collaboration between the artist Gillian Wearing, the playwright Leo Butler, the method-acting trainer Sam Rumbelow, and a small group of non-professional actors, the film sits somewhat uncomfortably between the realms of documentary and reality TV, rather than fiction film. Wearing, who won the Turner Prize in 1997, has often been aligned with her Young British Artist contemporaries - Sam Taylor-Wood, Sarah Lucas, Steve McQueen, and Tracy Emin. In a similar move to McQueen and Taylor-Wood in recent years, Wearing has shifted from short video-based work into feature-length film for cinematic release and distribution: SELF MADE is the result of this. Wearing's previous work included confessional, intimate videos both of herself, and of others. Her video piece, Confess All on Video. Don'T Worry You Will Be in Disguise. Intrigued? Call Gillian from 1994, invited participants to make intimate confessions or fabrications on camera while wearing face-distorting masks.

In SELF MADE however, the seven participants, selected from hundreds of applicants in London and Newcastle, are not physically disguised. Instead they make use of method acting training in order to imaginatively develop a film in which they, as non-professional actors, will star. According to Richard Porton's article on the film in Cineaste, the "method" in SELF MADE follows the shape of method acting developed by Lee Strasberg and the Actors Studio from the I950s onward, ${ }^{24}$ though SELF MADE itself makes no reference either to Strasberg or to Constantin Stanislawski, whose "System" greatly influenced Strasberg's "Method." In particular, the performance techniques depicted in SELF MADE are drawn from the personal memories and the sensory and affective recall of the participants. However, as Lucy Reynolds has pointed out, the structure of the film itself draws more from television cultures than it does from contemporary video art, "as a potent point of mediation between the individual's private and public selves - a space of performance that elevates the ordinary to the pitch of drama, where video technology can act as a conduit through which citizens can express themselves." ${ }^{25}$ SELF MADE lingers on the peripheries of reality TV, mass observation documentary, and performative drama.

In the context of this essay, and in order to explore the work of a female filmmaker, whose film does not specifically pertain to female or feminist representation, I want to turn briefly to a short speech by Audre Lorde, black feminist writer and poet. In an incandescent essay from 1984 , Lorde shoots down the rhetoric of "universal" feminism while delivering the closing remarks at an American conference on feminist theory. The essay, titled with quiet fury, "The Master's Tools 
Will Never Dismantle the Master's House," lambasts the conference at which she has been invited to speak for its failure to acknowledge the plurality and diversity of the feminisms it purports to uphold. She writes:

Advocating the mere tolerance of difference between women is the grossest reformism. It is a total denial of the creative function of difference in our lives. Difference must be not merely tolerated, but seen as a fund of necessary polarities between which our creativity can spark like a dialectic. [...] Difference is that raw and powerful connection from which our personal power is forged. ${ }^{26}$

Lorde's advocacy of an active and productive engagement with difference - ethnic, social, cultural, economic, and gendered, still resonates closely with more recent media battles about feminism and intersectionality, some 20 years after this piece was originally written. ${ }^{27}$ The fact that so little has changed, both in the recognition of difference, and in the recognition of differential and complementary modes of feminism, is a cause for some concern. If the ethics of film are to do with understanding how to live, how to die, how to speak, and how to listen then surely difference, and understanding, respecting and recognizing that difference, needs to lie at the heart of that thinking. I am not speaking about tolerating difference, or assimilating difference, but acknowledging that within any given community, and particularly communities of scholars, the operations of power emerge quickly and the traces of that power obliterate difference just as quickly. Any sense of collective endeavor, any use of the term "we" also runs the concomitant risk of silencing, eliding, and ignoring difference.

The concerns with the relationships of vision and the image to the speaking subject that I outlined earlier in the work of Mondzain inspired some of the thoughts I encountered when viewing Wearing's SELF MADE. In particular I want to raise two concepts from Mondzain, pertaining to the image: vision and imagination. Trained in classical philosophy, Mondzain is concerned with the Byzantine theological relations of monotheistic religion to concepts of image, vision, and power. ${ }^{28}$ She asks how images came to be seen by viewers as ways of transforming those viewers into speaking subjects, ${ }^{29}$ and is interested in the emergence of Christian Byzantine theology that made such a significant intervention in the cultural construction of vision. ${ }^{30}$ Mondzain's particular approach to vision plays on the twofold meaning of the term: vision as sight, and vision as the power of imagination. In her article "What Does Seeing an Image Mean?" she writes:

We do not see the world because we have eyes. Our eyes are opened by our ability to produce images, by our capacity to imagine. These capacities are why we need vision in order to be able to speak; this is why the blind can speak as long as their capacity to imagine is intact. ${ }^{3 \mathrm{I}}$ 
This partly phenomenological envisioning of the world, made visible by the possibility of a personal and cultural imaginary, is where Mondzain's thinking can usefully bring together the work of Neshat and Wearing. Vision and the imaginary - terms so familiar to any scholar of visual cultures - take on a specifically cultural dimension, from the perspective of philosophy itself. Mondzain is of course not the only female or feminist philosopher to reintroduce the significance of social and cultural difference to philosophy qua philosophy, where she historically situates the nature of the imaginary in a cultural and epistemological relationship to the image, and to vision. Mondzain is not explicitly a feminist philosopher, nor a philosopher of gender; nonetheless her concerns with vision and the imaginary also bring about parallels with contemporary feminist philosophers such as Michèle LeDoeuff. ${ }^{32}$ In an inverse sense, while not specifically a philosopher of cinema, LeDoeuff's work has been brought into astute contact with Film Studies through the work of Catherine Constable and Rosalind Galt. ${ }^{33}$

In her complex summary of many of her more lengthy discussions of iconoclasm, Mondzain writes:

[S]eeing the image is equivalent to detecting, in the visible, the presence of an absence. Any discourse on the image is nothing but an interminable oxymoron in which presence and absence, but also shadow and light, finitude and infinity, temporality and eternity, corruptibility and incorruptibility, passion and impassivity are constantly switching their meaning and changing places. ${ }^{34}$

Talking about images and vision inevitably must acknowledge difference, opposition, and incommensurability as well as a capacity for imagination. Acknowledging difference both as a philosophical concept and as a material and representational actuality therefore becomes a vital component of philosophical thinking and cinematic ethics. By doing so, we acknowledge the invisible repressions and authorities that are always at work, both in the philosophical imaginary and in the cinematic image.

I return to SELF MADE now in order to talk about the relationships between represented difference in the cinematic image and the image of selves performed in Wearing's film. Much of SELF MADE is occupied with the training that the participants undergo in order to release recalled emotion through controlled moments of imaginative performance. In an early sequence, the participants, including Asheq Akhtar, a humanitarian worker from London, are undertaking a sensememory exercise that requires them to imagine themselves immersed in a bath of water, which method-acting trainer Rumbelow asks them to visualize changing in temperature and water quality. The sequence, which films each of the participants at close range, focuses at some length on Asheq's obvious distress as he inhabits his sense memory of dirty bathwater. In an almost trance-like state of 
suffering, Asheq struggles to breathe and to utter the long, drawn-out "ah" sound that is a regular part of the Method warm-up exercise depicted on screen. When asked what he was experiencing at the end of the exercise, he states, "Different rooms, different baths, different types of baths... different cultures, different worlds, different people, different animals, different everything." Difference - and in particular the incommensurable difference between personal experience and the present moment - become a source of creative cinematic performance.

In a brief talking-head interview inset, Asheq mentions that he has "always been attracted to the darker side and people," citing his background as an immigrant in Newcastle in the context of I980s Britain. Subsequently, the camera's uncomfortable proximity to Asheq's weeping face is replaced with a more static and cinematically conventional series of shot-reverse-shots as Asheq then describes to Sam, the method-acting trainer, his vision of the white, middle-class family unit presented to him for his response in the workshop space in front of him.

The vision he describes is one that distinguishes mistrust, contempt, rage, disappointment, and the brief specter of Nazism and the Holocaust - references that Asheq mentions twice in quick succession in the two adjacent scenes. Asheq's distress and vulnerability are translated on screen into scorn, as he describes his reactions not just to this middle-class white family but also to their representation, off screen and on screen. In this sequence, it seems that difference - the difference of experience, of affective memory, of perception, creates both a performance of intense vulnerability and an articulation of mistrust and alterity that reverses dominant presentations of privilege and looking. The white family unit is revised through Asheq's description to reveal what discourses of privilege make absent: that socio-economic and racial privilege distorts creative capacity. What is revealed in Asheq's onscreen performance are the ways in which his experiences of ethnic difference and childhood trauma also make perceptible the powerful undercurrents of privilege and violence in onscreen performance.

Where I earlier discussed Mondzain's emphasis on notions of vision and image that elide and contain both what is visible and what is invisible, Asheq's particularity of vision emphasizes both the visible impact of socio-economic and ethnic privilege, and the "invisible" creative and personal limitations of these kinds of performance stereotypes. Furthermore, Asheq's imagination and his affective recall of life experiences bring about a creative and incisive critique of privilege, but in a manner where the legible traces of that affective recollection are not externally visible in his performance.

I want to recall again the words of Audre Lorde here, which seem to resonate with the creativity of Asheq's performance and the ethically uncomfortable vulnerability I see presented here on screen. Lorde writes: "Difference must be not merely tolerated, but seen as a fund of necessary polarities between which our 
creativity can spark like a dialectic. [...] Difference is that raw and powerful connection from which our personal power is forged." 35 Watching Asheq's performance - both in the image of himself projected through the sense-memory exercise and in his articulated vision of privileged others - is a powerful and emotionally wrought experience. His performances throughout the film reveal a wide range of fear, gentleness, tactility, warmth, rage, violence, regret, and tenderness that all imply the perspective of perceptual difference as "other" to socioeconomic and ethnic privilege. Nonetheless, these performances are always articulated through his body and his perception - a self-perception that is not fully commensurate with the ways in which his performance is represented on screen. In spite of their emotional intensity and physical proximity, sequences such as this in SELF MADE emphatically do not suggest a wellspring of shared experience among the participants but rather the intensity of singular experiences that bring creative performance into the present. By acknowledging the difference of his experiences, as working class, as a self-defined immigrant, as an abused child, as someone horrified by the misogyny he witnessed when his mother suffered domestic abuse, Asheq's performance through SELF MADE also offers an opportunity to reflect on affect as a mode of exploring the creative power of difference. Perhaps most interestingly, in SELF MADE the sources of that creative power are only made visible through a mode of reflexive, experimental documentary, whose parallels with reality television, video performance, and contemporary film art practice enable the film to both critique privilege in these contexts and to open up a creative space for the complex representation of non-white and/ or non-privileged performers.

\section{Conclusions: Women On Film - A New Experimentalism?}

This essay can only allow me to gesture towards what a restitution of difference in relation to contemporary experimental film might look like. Perhaps a starting ground for this is to reflect on the relations of power to vision and difference, to imagination and performance, to self-image and affect that I have outlined here. The cinematic language of performance in SELF MADE seems to gesture towards the creative capacity for articulating contextual difference that is also often disguised by dominant representations of white, male, middle-class performers on screen. Perhaps my best conclusion is to say that difference is a necessary vector that reminds us that no form of philosophical thinking is ever complete and that any aim for conceptual completion is an undesirable consequence of power itself. Feminist philosophies and philosophies of the image from Audre Lorde and Marie-José Mondzain, respectively, in their insistence upon qualities of difference, context, and violence, help to provoke new and creative encounters with the difference that is always there. 
In commenting on, and describing in detail, some aspects of the contemporary filmmaking of Shirin Neshat and Gillian Wearing, I have brought these works into contact with discourses of universality and difference. These two philosophical and ethical issues are, I believe, at the forefront of contemporary debates in feminist theory and film studies. It is not enough to focus on the representation of women in film nor on the conjunction of women and filmmaking, even in an experimental mode. While the relationalities of gender to representation and to creativity hold key stakes in current feminist debates, it seems all the more important to acknowledge the intersections of other relations: cultural, ethnic, and socio-economic. If there is something "new" in the experimental films I have discussed in this essay, this "newness" owes itself to a renewed vigor in understanding, and finding creative productivity, in difference. 